The Brock Review Volume 11 No. 2 (2011)

(C) Brock University

\title{
Rural Roots
}

\section{Kristine Thoreson}

As a Western Canadian artist, my work investigates methods through which we construct and deconstruct narratives of personal and cultural identity and the role of self-performance within these practices. My work is situated within the intersection of Performance Studies, visual art, and local scholarship. Through art I seek to enrich the growing body of knowledge regarding photography as a performance of identity, and to document personal experiences in the region of Southern Alberta. This photographic project is indicative of my tendency to work out in the landscape while not attempting to "capture" traditional landscape "scenery". My goal is instead to get to know a place, and to discover or resist some kind of personal, cultural or topographical attachment; it is to discover what it is that draws me in (or repels me). Thus with this project, I do not seek to do an ethnographic study of what the rural places around Calgary Alberta may mean to certain people. Rather, I am interested in the intersection of space with place and how we transform wide open space into meaningful place.

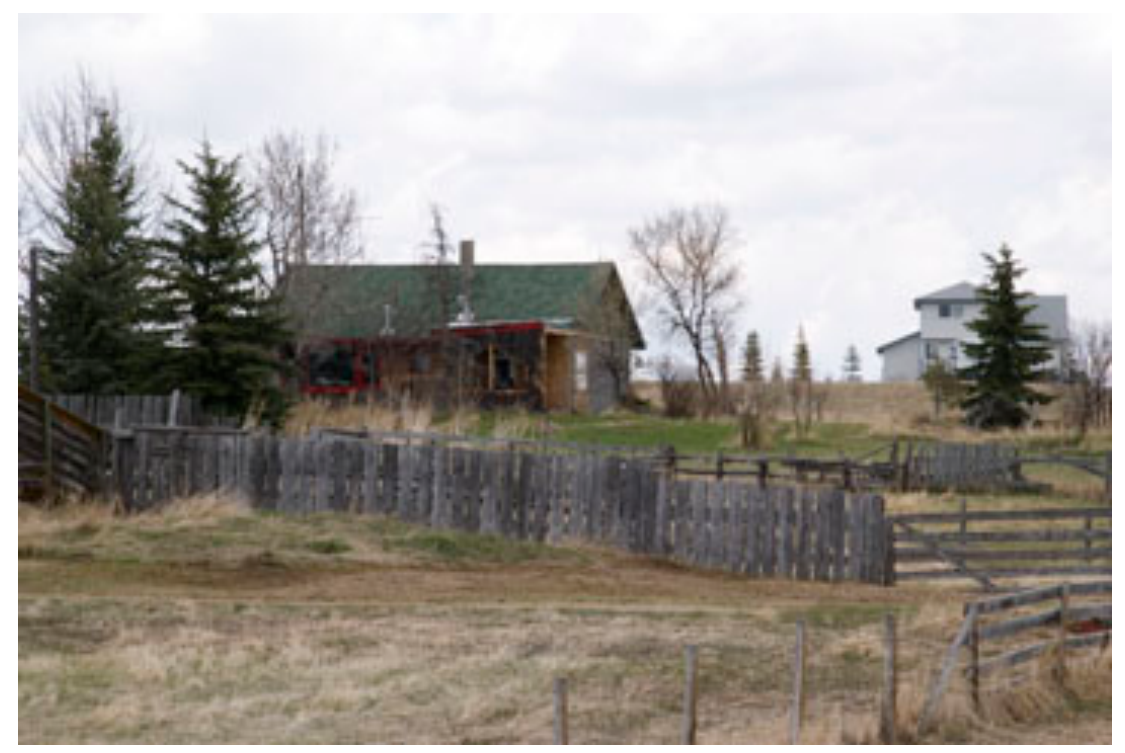




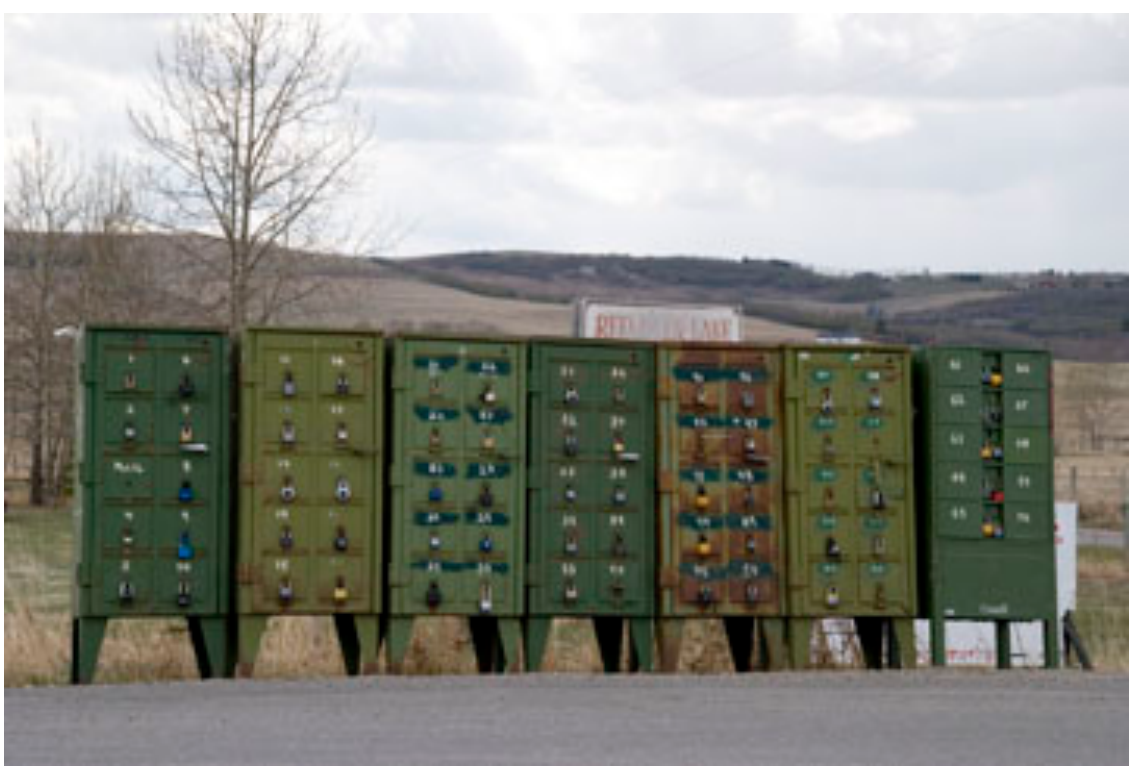

Kristine Thoreson, Box 28 (2010)

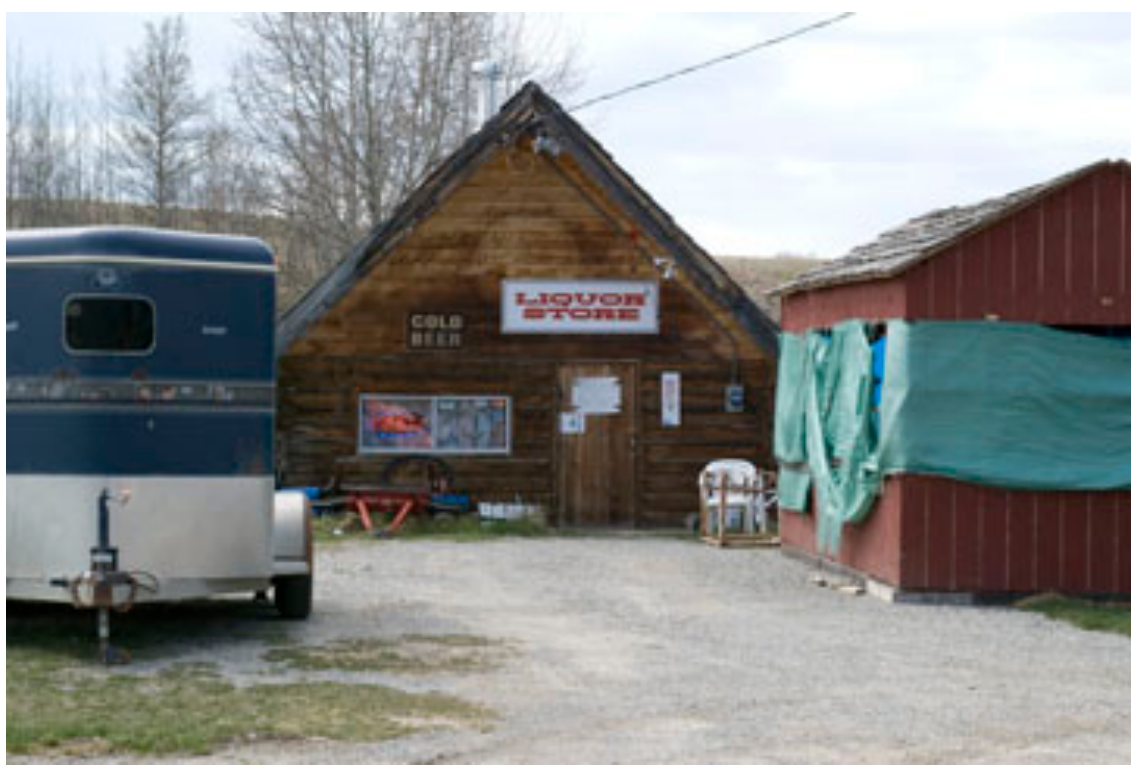

Kristine Thoreson, Press Bell for Service (2010) 


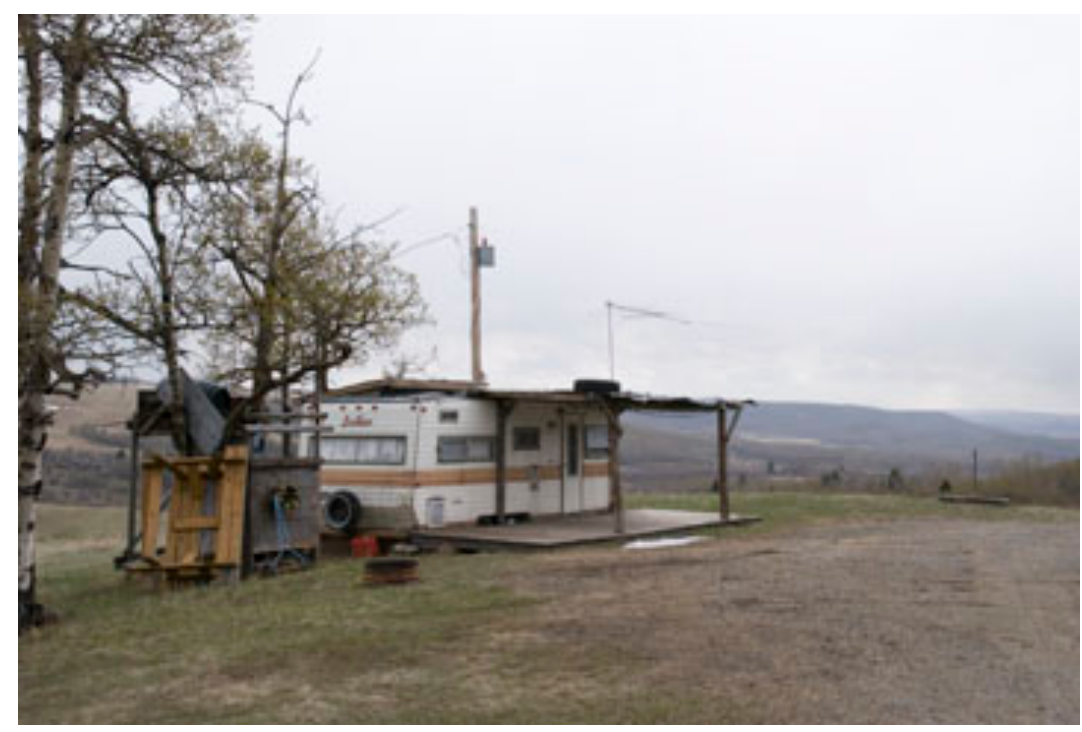

Kristine Thoreson, For Rent (2010)

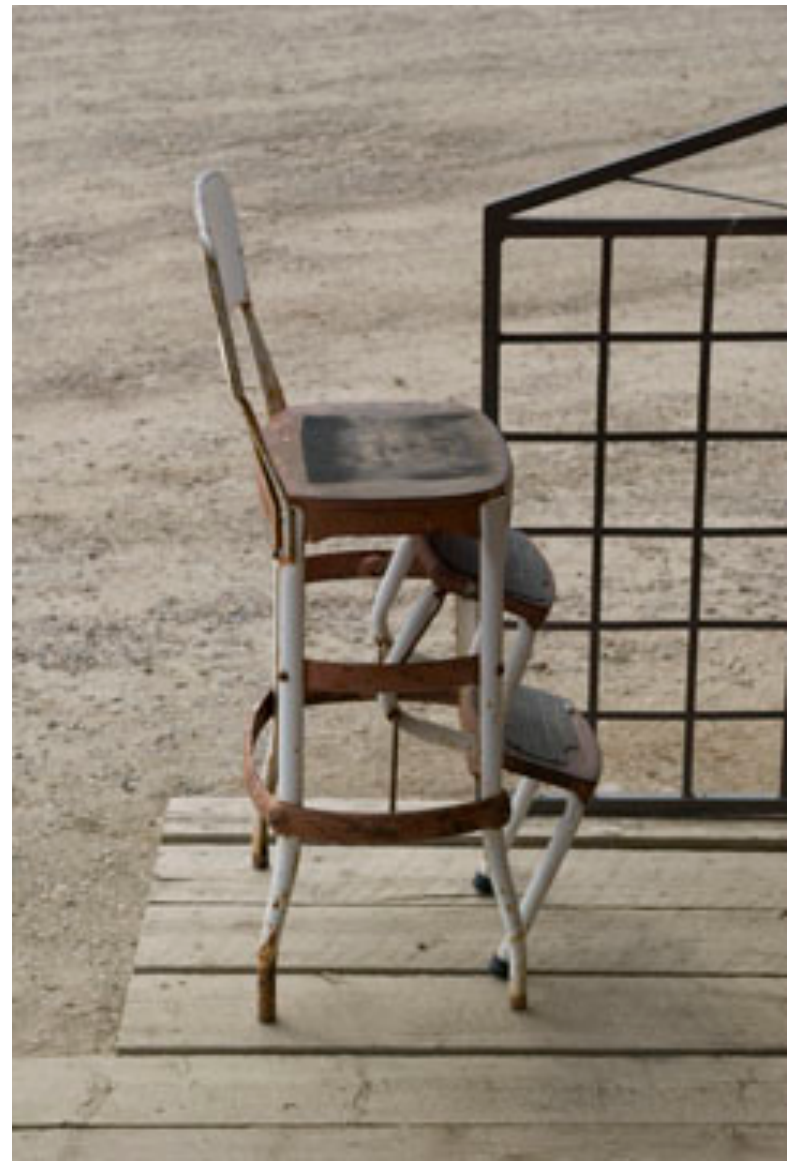

Kristine Thoreson, Sit a Spell (2010) 


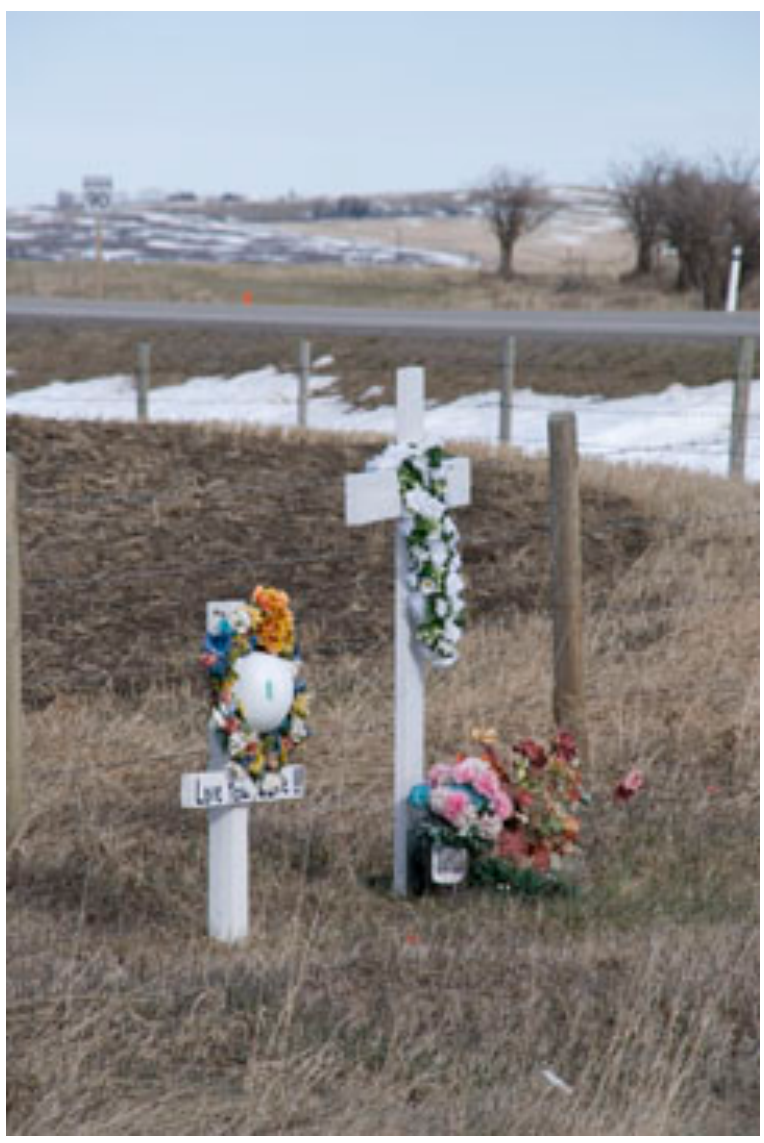

Kristine Thoreson, We Love You (2010)

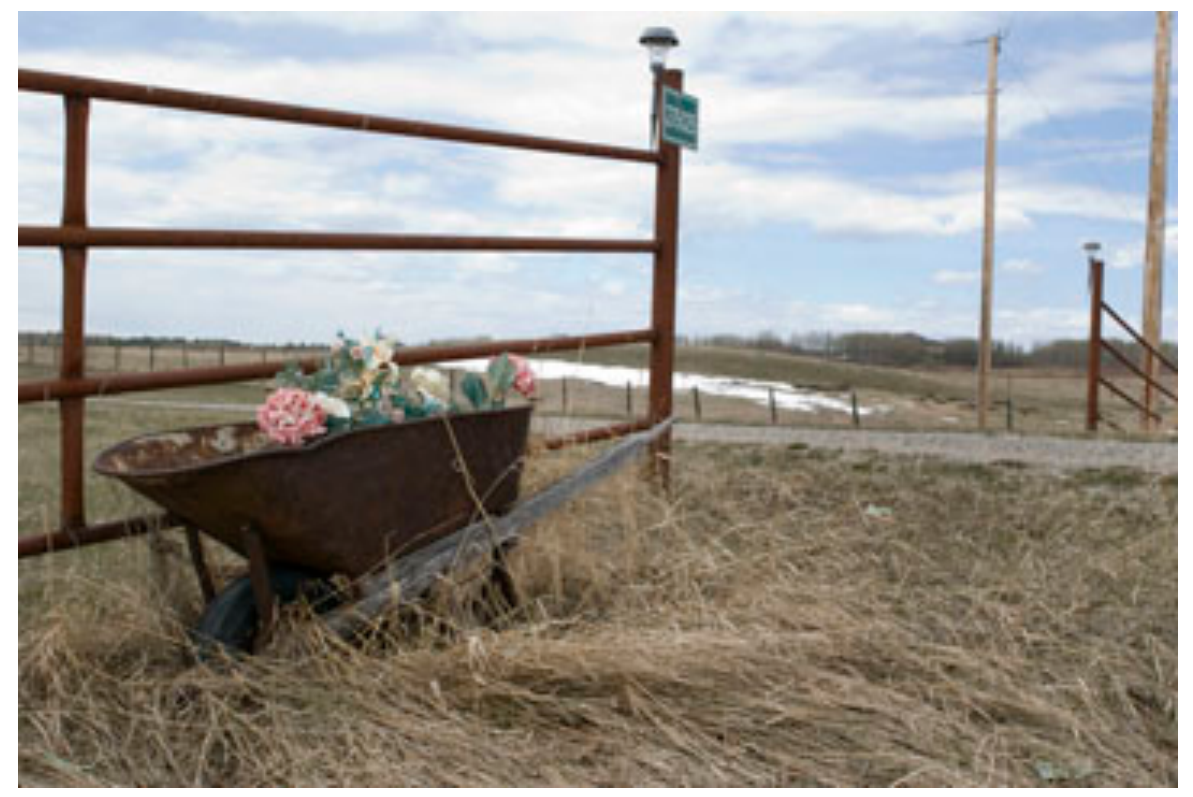

Kristine Thoreson, Welcome (2010) 